\title{
Tribbles homolog 2 (Trib2), a pseudo serine/ updates threonine kinase in tumorigenesis and stem cell fate decisions
}

\author{
Yu Fang ${ }^{1,2^{*}}$, Angelina Olegovna Zekiy ${ }^{3}$, Farhoodeh Ghaedrahmati ${ }^{4}$, Anton Timoshin ${ }^{5}$, Maryam Farzaneh ${ }^{6}$, \\ Amir Anbiyaiee $^{7}$ and Seyed Esmaeil Khoshnam ${ }^{8}$
}

\begin{abstract}
The family of Tribbles proteins play many critical nonenzymatic roles and regulate a wide range of key signaling pathways. Tribbles homolog 2 (Trib2) is a pseudo serine/threonine kinase that functions as a scaffold or adaptor in various physiological and pathological processes. Trib2 can interact with E3 ubiquitin ligases and control protein stability of downstream effectors. This protein is induced by mitogens and enhances the propagation of several cancer cells, including myeloid leukemia, liver, lung, skin, bone, brain, and pancreatic. Thus, Trib2 can be a predictive and valuable biomarker for the diagnosis and treatment of cancer. Recent studies have illustrated that Trib2 plays a major role in cell fate determination of stem cells. Stem cells have the capacity to self-renew and differentiate into specific cell types. Stem cells are important sources for cell-based regenerative medicine and drug screening. Trib2 has been found to increase the self-renewal ability of embryonic stem cells, the reprogramming efficiency of somatic cells, and chondrogenesis. In this review, we will focus on the recent advances of Trib2 function in tumorigenesis and stem cell fate decisions.
\end{abstract}

Keywords: Pluripotent stem cells, Tribbles homolog 2, Tumorigenesis, Pluripotency, Reprogramming, Stem cell fate, Regenerative medicine

\section{Background}

Tribbles homolog 2 (Trib2) is a pseudo serine/threonine kinase and a member of the Tribbles family that functions as a scaffold or adaptor in signaling pathways in a number of physiological and pathological processes [1-3]. The family of Tribbles proteins play many critical nonenzymatic roles and regulate a wide range of key signaling pathways such as mitogen-activated protein kinase (MAPKs), nuclear factor-kB (NF-kB), PI3K/AKT, and activating transcription factor 4 (ATF4) in healthy and pathological processes [4-6]. Trib2 can interact with

\footnotetext{
*Correspondence: 01693@aynu.edu.cn

${ }^{1}$ Anyang Center for Chemical and Pharmaceutical Engineering, College of Chemistry and Chemical Engineering, Anyang Normal University, Anyang 455000, Henan, People's Republic of China

Full list of author information is available at the end of the article
}

E3 ubiquitin ligases and control protein stability of downstream effectors [7]. Trib2 as a mitosis blocker regulates various cellular processes, including germ cell development, apoptosis, proliferation, lineage specification, reproduction, inflammation, innate immunity, and drug resistance [8-11]. It is known that Trib2 has diverse roles in neurological disorders, metabolic diseases, autoimmune and inflammatory diseases, arthritis, and a number of cancers (chronic myeloid leukemia, liver, melanoma, and ovarian) [3, 12, 13]. In human cancer, Trib2 as a cancer-associated pseudokinase and novel oncogene can enhance cell proliferation and stimulate cell cycle arrest [14]. Trib2, recently identified as the cause of cancer drug resistance $[15,16]$. There is substantial evidence that Trib2 can be a predictive and valuable biomarker for cancer diagnosis and treatment $[6,17]$. Recent studies original author(s) and the source, provide a link to the Creative Commons licence, and indicate if changes were made. The images or other third party material in this article are included in the article's Creative Commons licence, unless indicated otherwise in a credit line to the material. If material is not included in the article's Creative Commons licence and your intended use is not permitted by statutory regulation or exceeds the permitted use, you will need to obtain permission directly from the copyright holder. To view a copy of this licence, visit http://creativecommons.org/licenses/by/4.0/. The Creative Commons Public Domain Dedication waiver (http://creativeco mmons.org/publicdomain/zero/1.0/) applies to the data made available in this article, unless otherwise stated in a credit line to the data. 
have illustrated that Trib2 plays a major role in cell fate determination of stem cells [2]. Stem cells are undifferentiated cells that have the capacity to self-renew and differentiate into specific cell types $[18,19]$. Stem cells are classified into pluripotent (embryonic stem cells (ESCs) and induced pluripotent stem cells (iPSCs)), multipotent (mesenchymal stem cells (MSCs) and hematopoietic stem cells (HSCs)), and unipotent stem cells [20-22]. Human PSCs and MSCs are important sources for cellbased regenerative medicine, tissue engineering, and drug screening [23-25]. Trib2 has been found to increase the self-renewal ability of ESCs, the reprogramming efficiency of somatic cells, and chondrogenesis [2]. In this review, we will focus on the recent advances of Trib2 function in tumorigenesis and stem cell fate decisions.

\section{Structure and function of Trib2}

Tribbles (Trib) is a critical regulator of embryonic development that for the first time identified in Drosophila [26]. In the human genome, the Trib proteins have three homologs, including TRIB1, TRIB2, and TRIB3, with a single kinase-like and highly conserved domain that encodes pseudo-kinase proteins [9]. Trib2 contains an $\mathrm{N}$-terminal domain (PEST), a C-terminal E3 ligase-binding domain, and a pseudokinase domain with a Ser/Thr protein kinase-like domain (without a canonical 'DFG' (metal-binding) motif) [1, 26].

The $\mathrm{C}$-terminal domain has the HPW $[\mathrm{F} / \mathrm{L}]$ motif (targets MAPKK/MEK family members) and the conserved DQXVP [D/E] peptide motif (binds to COP1 E3 ubiquitin ligases) [27]. The pseudokinase domain has a unique cysteine-rich C-helix that binds with E3 ubiquitin ligases [28] (Fig. 1).

TRIB proteins through E3 ligase-dependent ubiquitination (pseudokinase mechanism) and scaffolding (with the MAPK and AKT pathway) have the potential to control cell proliferation, apoptosis, survival, and differentiation [27]. The family of Tribbles proteins can regulate a wide range of signaling pathways such as mitogen-activated protein kinase (MAPKs), nuclear factor- $k B$ (NF-kB), protein kinase $\mathrm{B}$ (PKB or $\mathrm{AKT}$ ), and activating transcription factor 4 (ATF4) [4-6]. In the Toll-like receptor (TLR) signaling pathway, Trib1 negatively controls the expression of CCAAT/enhancer-binding protein $\beta(\mathrm{C} / \mathrm{EBP} \beta)$ [29]. Trib1 and Trib2 are able to recruit the E3 ligase and induce C/EBP $\alpha$ and $C / E B P \beta$ degradation $[30,31]$. Therefore, TRIBs through the degradation of C/EBP transcription factors promote oncogenesis [6]. Trib3 has been shown to regulate serine-threonine kinase AKT (PKB), p65/rel A, and activating ATF4 [32-34]. Trib1 and Trib3 in response to various pro-inflammatory stimuli trigger the MAP kinase pathway and regulate the activator protein 1 (AP-1)-related pathway [35].
Little information is known about the role of Trib2 in mammals [9, 27]. Trib2 has a low affinity for ATP and further structural studies are required for the ATP-binding status of this protein $[6,14]$. Trib2 via a ubiquitinand proteasome-dependent pathway regulates the cell cycle in human cells $[31,36]$. It should be noted that both the Trib2 kinase domain and COP1 binding are essential for the ability of Trib2 to degrade C/EBP $\alpha$ [37]. Trib2 has been reported to be a pro-apoptotic molecule that stimulates apoptosis via a caspase-dependent mechanism [38]. Trib2 with the expression of pro- and anti-inflammatory immune modulators appears to be essential for innate immunity [39]. Trib2 as an important regulator of normal hematopoiesis can regulate the differentiation potential of intrathymic precursors and the checkpoints of thymopoiesis [11]. The function of monocytes and macrophages can be modulated by Trib2 [40, 41]. Trib2 has been shown to regulate the development of T-cell and erythroid cells $[42,43]$. This protein as an anti-inflammatory factor negatively regulates NF-kB (p100) activity in the TLR5 pathway [9, 44]. During follicular development, Trib2 increases the activity of the MAPK/ERK pathway and regulates granulosa cells (GCs) proliferation and function [45].

\section{Different roles of Trib2 in tumorigenesis}

Trib2 is a cancer-associated pseudokinase that can be induced by mitogens and enhances the propagation of several cancer cells, including myeloid leukemia, liver, lung, skin, bone, brain, and pancreatic [10, 46] (Table 1).

In normal murine hematopoiesis, TRIB2 function is necessary for the thymopoietic reaction to oncogenic stress [47]. In hematological malignancies, TRIB2 as a target gene of MEIS1, E2F1, and NOTCH1 participates in acute myeloid leukemia (AML) and T cell acute lymphoblastic leukemia (T-ALL) [42, 48, 49]. In human AML, Trib2 has been reported to be a negative regulator of $\mathrm{C} /$ EBP $\alpha$ expression and enhances AML progression [50]. In patient-derived human AML cells, Trib2 enhances the expression of anti-apoptotic B-cell lymphoma 2 (BCL2) [51]. In chronic myelogenous leukemia (CML), Trib2 through the ERK pathway increases cell proliferation and drug resistance [12]. Smad ubiquitination regulatory factor 1 (Smurf1) is a HECT-type E3 ubiquitin ligase that acts as a tumor enhancer or suppressor in various biological processes [52]. Trib2 by regulating the degradation of E3 ubiquitin ligase $\beta \operatorname{TrCP}, \mathrm{COP} 1$, and Smurf1 can inhibit the Wnt pathway and reduce cell propagation in myeloid leukemia [53]. In response to stress, TRIB2 as a tumor suppressor stimulates activation of p38 stress signaling in myeloid leukemia [54]. Thus, Trib2 may decrease the ability of leukaemia cells to propagate [54]. In T-ALL, Trib2 as a direct target of Notch1 decreases C/EBP $\alpha$ 


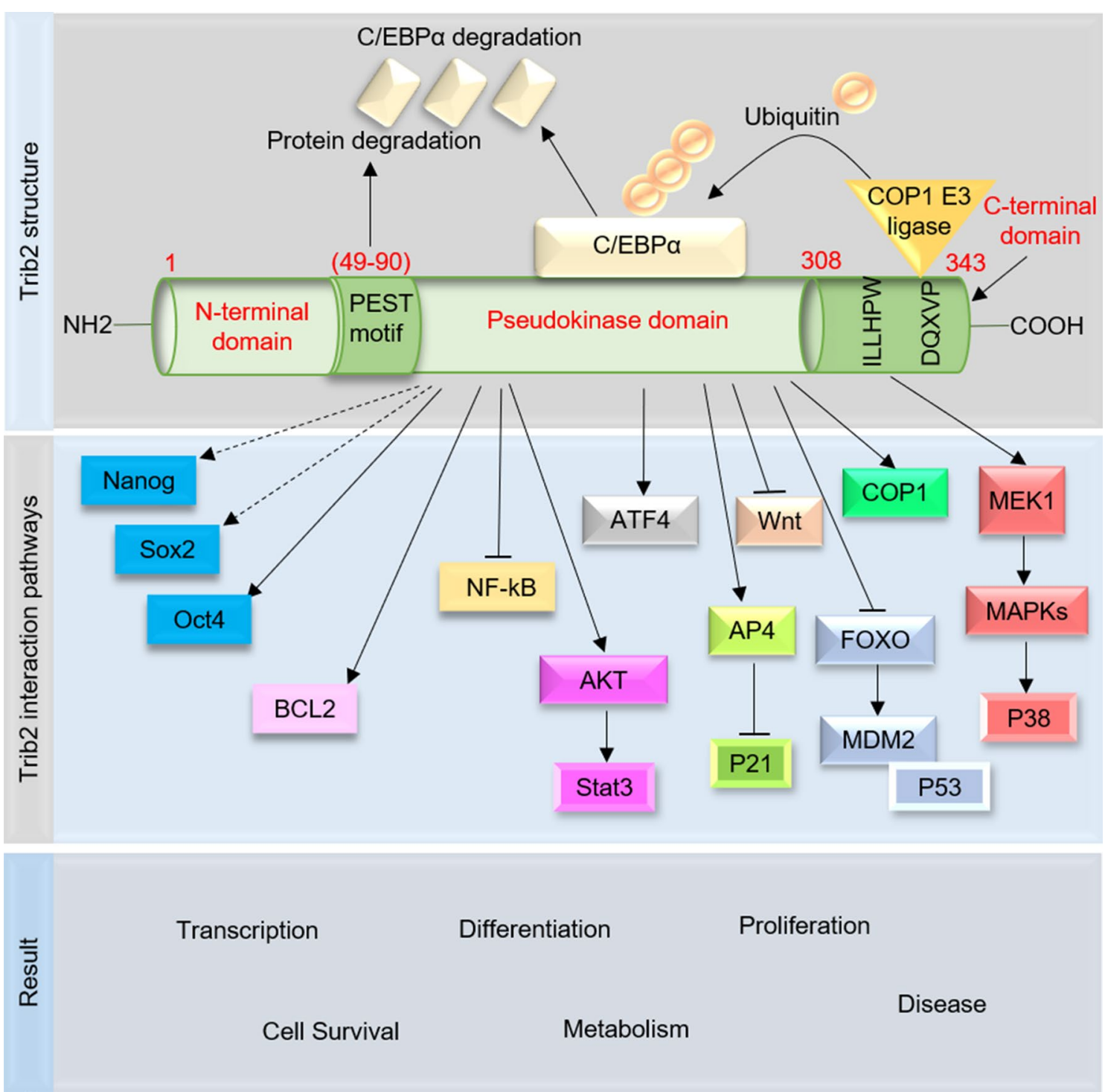

Fig. 1 Structural mechanism of Trib2. Trib2 contains an N-terminal domain (PEST), a C-terminal E3 ligase-binding domain, a and pseudokinase domain with a Ser/Thr protein kinase-like domain. The C-terminal domain has the HPW [F/L] motif (targets MAPKK/MEK family members) and the conserved DQXVP [D/E] peptide motif (binds to COP1 E3 ubiquitin ligases). Trib2 can recruit the E3 ligase and induce degradation of CCAAT/ enhancer-binding protein $\beta$ (C/EBP $\beta$ ). Trib2 regulates a wide range of key signaling pathways such as mitogen-activated protein kinase (MAPKs), nuclear factor-KB (NF-kB), protein kinase B (PKB or AKT), activating transcription factor 4 (ATF4), B-cell lymphoma 2 (BCL2), FOXO (forkhead box protein $O$ ), and activating enhancer-binding protein 4 (AP4)

expression and promotes the growth and maintenance of T-ALL cells [55]. Afatinib is a small-molecule protein kinase inhibitor that can promote the degradation of Trib2 in human AML cells [28].

Trib2 can be a target for the Wnt/ $\beta$-catenin pathway downstream and regulates liver cancer cell growth and transformation [7]. In liver cancer, Trib2 shows high stability and interacts with $\beta \operatorname{TrCP}$ to accelerate Yesassociated protein (YAP) stabilization (Hippo pathway) and promote cancer cell proliferation [56]. Trib2 with its associated E3 ligases can reduce ubiquitination of transcription factor 4 (TCF4) and $\beta$-catenin and decrease Wnt activity [57]. TRIB2 has been identified that interacts with poly $(\mathrm{rC})$ binding protein 2 (PCBP2) and triggers the Ubiquitin (Ub) proteasome system (UPS) to reduce Ub flux and decrease the oxidative damage. Therefore, UPS by increasing oxidative damage might be a suitable target against liver cancer [58].

In lung cancer, Trib2 binds with TRIM21 E3 ligase and decreases expression levels of C/EBP $\alpha$, which accelerates 
Table 1 Pro-tumor and anti-tumor roles of TRIB2

\begin{tabular}{|c|c|c|c|}
\hline Disease & Mechanism of action & Result & References \\
\hline \multicolumn{4}{|l|}{ Pro-tumor } \\
\hline \multirow[t]{2}{*}{ AML } & Suppresses C/EBPa expression & Enhances AML progression & [50] \\
\hline & Enhances the expression of anti-apoptotic BCL2 & Enhances AML progression & [51] \\
\hline CML & Stimulates the ERK pathway & Increases cell proliferation and drug resistance & [12] \\
\hline T-ALL & Decreases C/EBPa expression & Promotes the growth and maintenance of T-ALL cells & [55] \\
\hline \multirow[t]{2}{*}{ Liver cancer } & Increases YAP stabilization & Promotes cancer cell proliferation & [56] \\
\hline & Interacts with PCBP2 and triggers the UPS & Reduces Ub flux and decrease the oxidative damage & [58] \\
\hline Lung cancer & Decreases expression levels of C/EBPa & Accelerates cell proliferation and tumor growth & [59] \\
\hline Malignant melanomas & Suppresses FOXO & $\begin{array}{l}\text { Promotes cell proliferation, colony formation, maintenance, } \\
\text { and progression }\end{array}$ & [63] \\
\hline $\begin{array}{l}\text { Human melanoma tis- } \\
\text { sues and cell line }\end{array}$ & & Migration and invasion & [64] \\
\hline OS cell line & & Enhances the malignant capacity & [10] \\
\hline CRC & Suppresses p21 expression & $\begin{array}{l}\text { Improves cell growth and progression, and block cellular } \\
\text { senescence }\end{array}$ & [14] \\
\hline GBM & Interacts with MAP3K1 & Enhances resistance to chemotherapy and radiotherapy & [8] \\
\hline Pancreatic cancer tissue & Suppresses the p53/MDM2 complex & Promotes resistance to anti-cancer therapy & {$[66]$} \\
\hline LSCC & Interacts with XIST & Enhances proliferation and migration & [69] \\
\hline oscC & Interacts with TRIM & Facilitates the development of OSCC & [71] \\
\hline \multicolumn{4}{|l|}{ Anti-tumor } \\
\hline Myeloid leukemia & $\begin{array}{l}\text { Suppresses the Wnt pathway, stimulates activa- } \\
\text { tion of p38 stress signaling }\end{array}$ & Reduces cell propagation & [53] \\
\hline
\end{tabular}

$A M L$ acute myeloid leukemia, BCL2 B-cell lymphoma 2, CML chronic myelogenous leukemia, $T$ - $A L L$ T cell acute lymphoblastic leukemia, YAP yes-associated protein, FOXO Forkhead box protein O, OS osteosarcoma, CRC colorectal cancer, GBM glioblastoma; MAP3K1, MAP kinase kinase kinase 1, LSCC squamous cell carcinoma cells, XIST X inactivate-specific transcript, OSCC oral squamous cell carcinoma, TRIM tripartite motif, PCBP2 Poly (rC) binding protein 2, UPS Ubiquitin (Ub) proteasome system

cell proliferation and tumor growth [59]. Recent literature has reported that miR-511 and miR-1297 as tumor suppressor genes decrease Trib2 expression and reduce lung adenocarcinoma cell proliferation [60]. Substantial evidence has shown that miR-206 and miR-140 are Smad3-related miRNAs that inhibit Trib2 expression, induce cell death, and decrease cell proliferation [61].

In malignant melanomas, Trib2 is overexpressed and inhibited FOXO (forkhead box protein $\mathrm{O}$ ) tumor suppressor activity [62]. Thus, Trib2 is important in cell proliferation, colony formation, maintenance, and progression of melanoma cells [63]. Recent data revealed that circular RNAs (circRNA)-0084043 can interact with miR-429 and positively regulate TRIB2 expression. Trib2, circRNA-0084043, and miR-429 are the leading causes of migration and invasion in human melanoma tissues and cell lines [64]. Members from the thiazolidinediones (TZDs) family was reported to overcome cell drug resistance in Trib2-positive cancer cells [15]

Trib2 has been found to enhance the malignant capacity of osteosarcoma (OS) cell line (malignant bone tumors). miR-509-5p as a tumor suppressor can target Trib2 and suppress cell propagation and migration in OS cell lines [10].
The $\mathrm{p} 53 / \mathrm{p} 21$ pathway is thought to be a critical regulator of the cell cycle and cellular senescence [65]. In colorectal cancer (CRC), Trib2 binds with activating enhancer-binding protein 4 (AP4) to suppress p21 expression, improve cell growth and progression, and block cellular senescence [14].

In Glioblastoma (GBM), Trib2 interacts with MAP kinase kinase kinase 1 (MAP3K1) and enhances resistance to temozolomide (TMZ) chemotherapy and radiotherapy [8].

In primary pancreatic cancer tissue, Trib2 protein has been shown to block FOXO activation, disrupt the p53/MDM2 complex (a negative feedback loop for cancer therapy), stimulate the serine/threonine protein kinase AKT, reduce cell death induced by PI3K inhibitors, and promote resistance to anti-cancer therapy [66, 67]. Recent evidence suggests that ZEB1-AS1 as a long non-coding RNA (lncRNA) by regulating miR-505-3p/ TRIB2 axis enhances the growth, viability, and invasion of pancreatic cancer cells [68].

$\mathrm{X}$ inactivate-specific transcript (XIST) is a lncRNA, which was recently proposed to interact with miR$125 \mathrm{~b}-5 \mathrm{p}$, promote Trib2 expression, and enhance 


\section{The function of Trib2 in stem cell fate decisions}

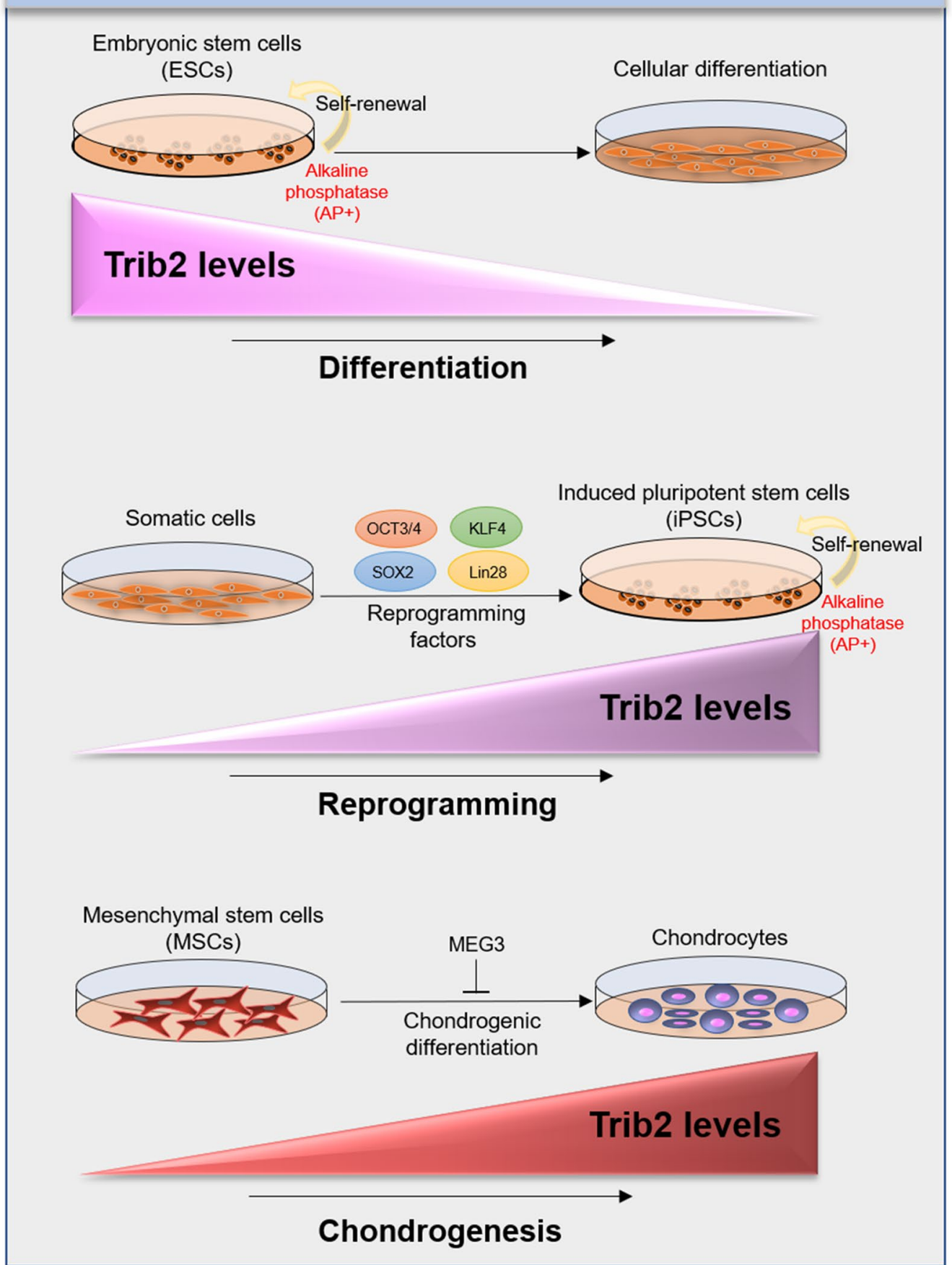

Fig. 2 The function of Trib2 in stem cell fate decisions. Human ESCs are derived from donated pre-implantation embryos and the inner cell mass (ICM) of the blastocyst. Human iPSCs are ESC-equivalent cells that can be derived by introducing core reprogramming factors (Oct4, Sox2, Nanog, and KIf4 or OSKM) into embryonic fibroblasts. Trib2 is necessary for colony formation, alkaline phosphatase (AP) activity, and self-renewal ability of ESCS and iPSCS. MEG3 can downregulate Trib2 expression and suppress the chondrogenic differentiation of synovium-derived MSCs 
proliferation and migration of laryngeal squamous cell carcinoma (LSCC) cells [69].

Tripartite motif (TRIM) protein has an important role in the pathogenesis of oral squamous cell carcinoma (OSCC) [70]. TRIM via modulating the TRIB2-MAPK signal axis can promote abnormal expression of interleukin-6 (IL-6) and disrupt TH1/TH2 balance (interferongamma (IFN- $\gamma$ ) and IL-4) in T cells [71].

Therefore, Trib2 may be a suitable biomarker for the cancer diagnosis, because it shows high expression in malignant cells [27].

\section{The function of Trib2 in stem cell fate decisions}

Human ESCs are derived from donated pre-implantation embryos and the inner cell mass (ICM) of the blastocyst [72, 73]. A recent study has reported that Trib2 may be necessary for colony formation, alkaline phosphatase (AP) activity, and self-renewal ability of ESCs [2]. Trib2 interacts with Oct 4 and regulates the expression of the pluripotency marker genes. Thus, loss of Trib2 expression is associated with differentiation of ESCs [2]. Human iPSCs are ESC-equivalent cells that can be derived by introducing core reprogramming factors (Oct4, Sox2, Nanog, and Klf4 or OSKM) into embryonic fibroblasts $[74,75]$. Trib2 plays an important role in the reprogramming of somatic cells [2]. It has been shown that Trib2 knockdown reduces the reprogramming efficiency and the expression of OSKM in the generated cells. While colony formation and AP activity in OSKM/Trib2 transduced cells were higher than cells transduced with the OSKM factors. Trib2 through the Trib2-Oct4 complex can facilitate the generation of iPSCs from somatic cells [2].

It has been reported that Trib2 through a proteasomedependent mechanism induces the degradation of $\mathrm{C} /$ EBP $\beta$ and suppresses adipocyte differentiation at an early stage $[76,77]$. The differentiation of myeloid progenitor cells can be suppressed with the MLL-TET1 (MT1) fusion protein. This protein induces Trib2 mRNA and protein expression and decreases C/EBP $\alpha$ expression. Thus, Trib2 is important to keep leukemic cells in an undifferentiated state [78]. Trib2 has been found to increase chondrogenesis from MSCs. MEG3 as a lncRNA has been reported to upregulate enhancer zeste homolog 2 (EZH2) methyltransferase and downregulate Trib2 expression to suppress the chondrogenic differentiation of synovium-derived MSCs [79] (Fig. 2).

\section{Challenges and prospective}

The expression of TRIB2 in tumor tissues and cell lines is significantly increased [66]. High TRIB2 expression was shown to be essential in melanoma progression, lung tumorigenesis, liver and colon tumors $[3,26,58,80]$.
Hence, TRIB2 can be a novel targeted therapeutic and strong candidate against chemoresistant cancers [81]. However, the exact mechanism of TRIB2 as an adaptor protein in cancer is still controversial and remains unclear [82]. Therefore, multiple genetic and epigenetic mutations should be assessed to identify the specific interaction of TRIB2 with partner proteins [83].

\section{Conclusion}

We have highlighted various studies, which provide evidence of Trib2 protein as an attractive target for cancer therapy. Although Trib2 has a key role in multiple physiological and pathological processes, much effort will be required to find its relevance to stem cell fate decisions. It can be concluded that Trib2 may represent a potential target in basic research and cancer treatment.

\section{Abbreviations \\ AP: Alkaline phosphatase; AP-1: Activator protein 1; AML: Acute myeloid leuke- mia; ATF4: Activating transcription factor 4; BCL2: B-cell lymphoma 2; C/EBPB: CCAAT/enhancer-binding protein $\beta ;$ CML: Chronic myelogenous leukemia; ESCs: Embryonic stem cells; EZH2: Enhancer zeste homolog 2; FOXO: Forkhead box protein O; GCs: Granulosa cells; HSCs: Hematopoietic stem cells; IPSCs: Induced pluripotent stem cells; MAPKs: Mitogen-activated protein kinase; MT1: MLL-TET1; MSCs: Mesenchymal stem cells; NF-kB: Nuclear factor-KB; Smurf1: Smad ubiquitination regulatory factor 1; TCF 4: Transcription factor 4 ; TLR: Toll-like receptor; T-ALL:T cell acute lymphoblastic leukemia; Trib2: Trib- bles homolog 2; TZDs: Thiazolidinediones; XIST: X inactivate-specific transcript: YAP:Yes-associated protein.}

\section{Acknowledgements}

Fund Name: Henan Joint Fund of National Natural Science Foundation of China (Grant No.: U1804188). Project Name: The study on the novel F-18-labeled and EGFR-targeted small molecular radiopharmaceuticals for the early diagnosis of esophageal cancer.

\section{Authors' contributions}

YF, AOZ, and MF have been involved in drafting the manuscript. FG and AA have made substantial contributions to the revising of the manuscript and the design of the Figures. AT and SEK have made a substantial contribution to the writing and revising of the manuscript and the figures. All authors read and approved the final manuscript.

\section{Funding}

Not applicable.

\section{Availability of data and materials}

The datasets used and/or analyzed during the current study are available from the corresponding author on reasonable request.

\section{Declarations}

Ethics approval and consent to participate Not applicable.

Consent for publication Not applicable.

Competing interests

The authors declare that there is no competing interests. 


\begin{abstract}
Author details
1 Anyang Center for Chemical and Pharmaceutical Engineering, College of Chemistry and Chemical Engineering, Anyang Normal University, Anyang 455000, Henan, People's Republic of China. ${ }^{2}$ Key Laboratory of New Opto-Electronic Functional Materials of Henan Province, College of Chemistry and Chemical Engineering, Anyang Normal University, Anyang 455000, Henan, People's Republic of China. ${ }^{3}$ Department of Prosthetic Dentistry, Sechenov First Moscow State Medical University, Moscow, Russia. ${ }^{4}$ Department of Immunology, School of Medicine, Isfahan University of Medical Sciences, Isfahan, Iran. ${ }^{5}$ Independent researcher, Moscow, Russia. ${ }^{6}$ Fertility, Infertility and Perinatology Research Center, Ahvaz Jundishapur University of Medical Sciences, Ahvaz, Iran. ${ }^{7}$ Department of Surgery, School of Medicine, Ahvaz Jundishapur University of Medical Sciences, 61357-15794 Ahvaz, Iran. ${ }^{8}$ Persian Gulf Physiology Research Center, Medical Basic Sciences Research Institute, Ahvaz Jundishapur University of Medical Sciences, Ahvaz, Iran.
\end{abstract}

Received: 23 December 2020 Accepted: 16 February 2021 Published online: 01 April 2021

\section{References}

1. Bailey FP, Byrne DP, Oruganty K, Eyers CE, Novotny CJ, Shokat KM, Kannan N, Eyers PA. The Tribbles 2 (TRB2) pseudokinase binds to ATP and autophosphorylates in a metal-independent manner. Biochem J. 2015;467:47-62.

2. Do EK, Park JK, Cheon HC, Kwon YW, Heo SC, Choi EJ, Seo JK, Jang IH, Lee $\mathrm{SC}$, Kim JH. Trib2 regulates the pluripotency of embryonic stem cells and enhances reprogramming efficiency. Exp Mol Med. 2017;49:e401-e401.

3. Yokoyama T, Nakamura T. Tribbles in disease: signaling pathways important for cellular function and neoplastic transformation. Cancer Sci. 2011;102:1115-22.

4. Yokoyama T, Kanno Y, Yamazaki Y, Takahara T, Miyata S, Nakamura T. Trib1 links the MEK1/ERK pathway in myeloid leukemogenesis. Blood J Am Soc Hematol. 2010;116:2768-75.

5. Hong B, Zhou J, Ma K, Zhang J, Xie H, Zhang K, Li L, Cai L, Zhang N, Zhang Z. TRIB3 promotes the proliferation and invasion of renal cell carcinoma cells via activating MAPK signaling pathway. Int J Biol Sci. 2019;15:587.

6. Richmond L, Keeshan K. Pseudokinases: a tribble-edged sword. FEBS J. 2019;287(19):4170-82.

7. Wang J, Zhang Y, Weng W, Qiao Y, Ma L, Xiao W, Yu Y, Pan Q, Sun F. Impaired phosphorylation and ubiquitination by p70 S6 kinase (p70S6K) and Smad ubiquitination regulatory factor 1 (Smurf1) promote tribbles homolog 2 (TRIB2) stability and carcinogenic property in liver cancer. J Biol Chem. 2013;288:33667-81.

8. Wang J, Zuo J, Wahafu A, Wang MD, Li RC, Xie WF. Combined elevation of TRIB2 and MAP3K1 indicates poor prognosis and chemoresistance to temozolomide in glioblastoma. CNS Neurosci Ther. 2020;26:297-308.

9. Wei S-C, Rosenberg IM, Cao Z, Huett AS, Xavier RJ, Podolsky DK. Tribbles 2 (Trib2) is a novel regulator of toll-like receptor 5 signaling. Inflamm Bowel Dis. 2012;18:877-88.

10. Guo J, Wu Q, Peng X, Yu B. miR-509-5p inhibits the proliferation and invasion of osteosarcoma by targeting TRIB2. BioMed Res Int. 2019;2019:2523032.

11. Liang KL, O'Connor C, McCarthy TV, Keeshan K. Investigation of the role of TRIB2 in normal murine hematopoiesis. Exp Hematol. 2015;43:S77.

12. Ma X, Zhou X, Qu H, Ma Y, Yue Z, Shang W, Wang P, Xie S, Li Y, Sun Y. TRIB2 knockdown as a regulator of chemotherapy resistance and proliferation via the ERK/STAT3 signaling pathway in human chronic myelogenous leukemia K562/ADM cells. Oncol Rep. 2018;39:1910-8.

13. Tanaka S, Honda Y, Honda M, Yamada H, Honda K, Kodama T. Anti-Tribbles Pseudokinase 2 (TRIB2)-immunization modulates hypocretin/orexin neuronal functions. Sleep. 2017;40(1):1-10.

14. Hou Z, Guo K, Sun X, Hu F, Chen Q, Luo X, Wang G, Hu J, Sun L. TRIB2 functions as novel oncogene in colorectal cancer by blocking cellular senescence through AP4/p21 signaling. Mol Cancer. 2018;17:172.

15. Sousa-Coelho A. Targeting TRIB2 expression with oral antidiabetic drugs to overcome tumour malignancy and drug-resistance. Eur J Pub Health. 2020;30(ckaa040):058.
16. Machado S, Silva A, Sousa-Coelho D, Luísa A, Duarte I, Grenho I, Santos B, Mayoral-Varo V, Megias D, Sánchez-Cabo F. Harmine and piperlongumine revert TRIB2-mediated drug resistance. Cancers. 2020;12:3689.

17. Chen Y, Xu L, Lin RYT, Müschen M, Koeffler HP. Core transcriptional regulatory circuitries in cancer. Oncogene. 2020;39:6633-46.

18. Xia H, Li X, Gao W, Fu X, Fang RH, Zhang L, Zhang K. Tissue repair and regeneration with endogenous stem cells. Nat Rev Mater. 2018;3:174-93.

19. Beumer J, Clevers H. Cell fate specification and differentiation in the adult mammalian intestine. Nat Rev Mol Cell Biol. 2021;22(1):39-53.

20. Farzaneh M, Derakhshan Z, Hallajzadeh J, Sarani NH, Nejabatdoust A, Khoshnam SE. Suppression of TGF- $\beta$ and ERK signaling pathways as a new strategy to provide rodent and non-rodent pluripotent stem cells. Curr Stem Cell Res Ther. 2019;14:466-73.

21. Kolagar T, Farzaneh M, Nikkar N, Anbiyaiee A, Heydari E, Khoshnam S. Human pluripotent stem cells in neurodegenerative diseases: potentials, advances, and limitations. Curr Stem Cell Res Ther. 2019;15:102-10.

22. Kolios G, Moodley Y. Introduction to stem cells and regenerative medicine. Respiration. 2013;85:3-10.

23. Farzaneh M, Anbiyaiee A, Khoshnam SE. Human pluripotent stem cells for spinal cord injury. Curr Stem Cell Res Ther. 2020;15:135-43.

24. Liu G, David BT, Trawczynski M, Fessler RG. Advances in pluripotent stem cells: history, mechanisms, technologies, and applications. Stem Cell Rev Rep. 2020;16:3-32.

25. Zhao C, Ikeya M. Generation and applications of induced pluripotent stem cell-derived mesenchymal stem cells. Stem Cells Int. 2018;2018:9601623-9601623.

26. Stein SJ, Mack EA, Rome KS, Pear WS. Tribbles in normal and malignant haematopoiesis. Biochem Soc Trans. 2015;43:1112-5.

27. Eyers PA, Keeshan K, Kannan N. Tribbles in the 21st century: the evolving roles of tribbles pseudokinases in biology and disease. Trends Cell Biol. 2017;27:284-98.

28. Foulkes DM, Byrne DP, Yeung W, Shrestha S, Bailey FP, Ferries S, Eyers CE, Keeshan K, Wells C, Drewry DH. Covalent inhibitors of EGFR family protein kinases induce degradation of human Tribbles 2 (TRIB2) pseudokinase in cancer cells. Sci Signal. 2018;11:549.

29. Yamamoto M, Uematsu S, Okamoto T, Matsuura Y, Sato S, Kumar H, Satoh T, Saitoh T, Takeda K, Ishii KJ. Enhanced TLR-mediated NF-IL6-dependent gene expression by Trib1 deficiency. J Exp Med. 2007;204:2233-9.

30. Foulkes DM. Biochemical analysis of Tribbles 2 pseudokinase using repurposed kinase inhibitors. The University of Liverpool (United Kingdom); 2018.

31. Salome M, Campos J, Keeshan K. TRIB2 and the ubiquitin proteasome system in cancer. Biochem Soc Trans. 2015;43:1089-94.

32. Ord D, Ord T. Mouse NIPK interacts with ATF4 and affects its transcriptional activity. Exp Cell Res. 2003;286:308-20.

33. Wu M, Xu LG, Zhai Z, Shu HB. SINK is a p65-interacting negative regulator of NF-kappaB-dependent transcription. J Biol Chem. 2003;278:27072-9.

34. Du K, Herzig S, Kulkarni RN, Montminy M. TRB3: a tribbles homolog that inhibits Akt/PKB activation by insulin in liver. Science. 2003;300:1574-7.

35. Kiss-Toth E, Bagstaff SM, Sung HY, Jozsa V, Dempsey C, Caunt JC, Oxley KM, Wyllie DH, Polgar T, Harte M, et al. Human tribbles, a protein family controlling mitogen-activated protein kinase cascades. J Biol Chem. 2004; $279: 42703-8$

36. Liang KL, Paredes R, Carmody R, Eyers PA, Meyer S, McCarthy TV, Keeshan K. Human TRIB2 oscillates during the cell cycle and promotes ubiquitination and degradation of CDC25C. Int J Mol Sci. 2016;17:1378.

37. Keeshan K, Bailis W, Dedhia PH, Vega ME, Shestova O, Xu L, Toscano K, Uljon SN, Blacklow SC, Pear WS. Transformation by Tribbles homolog 2 (Trib2) requires both the Trib2 kinase domain and COP1 binding. Blood. 2010;116:4948-57.

38. Lin KR, Lee SF, Hung CM, Li CL, Yang-Yen HF, Yen JJ. Survival factor withdrawal-induced apoptosis of TF-1 cells involves a TRB2-Mcl-1 axisdependent pathway. J Biol Chem. 2007;282:21962-72.

39. Rowan AD, Litherland GJ. Tribbles and arthritis: what are the links? Biochem Soc Trans. 2015;43:1051-6.

40. Deng J, James $\mathrm{CH}$, Patel L, Smith A, Burnand KG, Rahmoune H, Lamb JR, Davis B. Human tribbles homologue 2 is expressed in unstable regions of carotid plaques and regulates macrophage IL-10 in vitro. Clin Sci. 2009;116:241-8 
41. Eder K, Guan H, Sung HY, Ward J, Angyal A, Janas M, Sarmay G, Duda E, Turner M, Dower SK. Tribbles-2 is a novel regulator of inflammatory activation of monocytes. Int Immunol. 2008;20:1543-50.

42. Liang KL, O'Connor C, Veiga JP, McCarthy TV, Keeshan K. TRIB2 regulates normal and stress-induced thymocyte proliferation. Cell Discov. 2016;2:15050-15050.

43. Lin K-R, Yang-Yen H-F, Lien H-W, Liao W-H, Huang C-J, Lin L-I, Li C-L, Yen JJY. Murine tribbles homolog 2 deficiency affects erythroid progenitor development and confers macrocytic anemia on mice. Sci Rep. 2016;6:31444-31444.

44. Johnston J, Basatvat S, Ilyas Z, Francis S, Kiss-Toth E. Tribbles in inflammation. Biochem Soc Trans. 2015;43:1069-74

45. Warma A, Ndiaye K. Functional effects of Tribbles homolog 2 in bovine ovarian granulosa cellst. Biol Reprod. 2020;102:1177-90.

46. Colaço LG. Investigating the role and function of Tribbles 2 (TRIB2) in drug resistance within cancer; 2014.

47. Liang KL, O'Connor C, Veiga JP, McCarthy TV, Keeshan K. TRIB2 regulates normal and stress-induced thymocyte proliferation. Cell Discov. 2016;2:15050.

48. Argiropoulos B, Palmqvist L, Yung E, Kuchenbauer F, Heuser M, Sly LM, Wan A, Krystal G, Humphries RK. Linkage of Meis1 leukemogenic activity to multiple downstream effectors including Trib2 and Ccl3. Exp Hematol. 2008:36:845-59.

49. Rishi L, Hannon M, Salomè M, Hasemann M, Frank AK, Campos J, Timoney J, O'Connor C, Cahill MR, Porse B, Keeshan K. Regulation of Trib2 by an E2F1-C/ EBPa feedback loop in AML cell proliferation. Blood. 2014;123:2389-400.

50. Keeshan K, He Y, Wouters BJ, Shestova O, Xu L, Sai H, Rodriguez CG, Maillard I, Valk P, Carroll M. Tribbles homolog 2 (Trib2) inactivates C/EBPalpha and causes acute myelogenous leukemia. American Society of Hematology; 2006

51. O'Connor C, Yalla K, Salomé M, Moka HA, Castañeda EG, Eyers PA, Keeshan K. Trib2 expression in granulocyte-monocyte progenitors drives a highly drug resistant acute myeloid leukaemia linked to elevated BCl2. Oncotarget. 2018;9:14977-92.

52. Fu L, Cui C-P, Zhang X, Zhang L. The functions and regulation of Smurfs in cancers. Seminars in Cancer Biology; 2019.

53. Salomé M, Magee A, Yalla K, Chaudhury S, Sarrou E, Carmody RJ, Keeshan K. A Trib2-p38 axis controls myeloid leukaemia cell cycle and stress response signalling. Cell Death Dis. 2018;9:1-17.

54. Salomé M, Magee A, Yalla K, Chaudhury S, Sarrou E, Carmody RJ, Keeshan K. A Trib2-p38 axis controls myeloid leukaemia cell cycle and stress response signalling. Cell Death Dis. 2018;9:443.

55. Stein SJ, Mack EA, Rome KS, Pajcini KV, Ohtani T, Xu L, Li Y, Meijerink JP, Faryabi RB, Pear WS. Trib2 suppresses tumor initiation in Notch-driven T-ALL. PLOS ONE. 2016;11:e0155408.

56. Wang J, Park J-S, Wei Y, Rajurkar M, Cotton JL, Fan Q, Lewis BC, Ji H, Mao J. TRIB2 acts downstream of Wnt/TCF in liver cancer cells to regulate YAP and C/EBPa function. Mol Cell. 2013;51:211-25.

57. Xu S, Tong M, Huang J, Zhang Y, Qiao Y, Weng W, Liu W, Wang J, Sun F. TRIB2 inhibits Wnt/ $\beta$-Catenin/TCF4 signaling through its associated ubiquitin E3 ligases, $\beta$-TrCP, COP1 and Smurf1, in liver cancer cells. FEBS Lett. 2014;588:4334-41.

58. Guo S, Chen Y, Yang Y, Zhang X, Ma L, Xue X, Qiao Y, Wang J. TRIB2 modulates proteasome function to reduce ubiquitin stability and protect liver cancer cells against oxidative stress. Cell Death Dis. 2021;12:42.

59. Grandinetti K, Stevens T, Ha S, Salamone R, Walker J, Zhang J, Agarwalla S, Tenen D, Peters E, Reddy V. Overexpression of TRIB2 in human lung cancers contributes to tumorigenesis through downregulation of C/EBPa. Oncogene. 2011;30:3328-35.

60. Zhang C, Chi YL, Wang PY, Wang YQ, Zhang YX, Deng J, Lv CJ, Xie SY. miR-511 and miR-1297 inhibit human lung adenocarcinoma cell proliferation by targeting oncogene TRIB2. PLoS ONE. 2012;7:e46090.

61. Zhang Y-X, Yan Y-F, Liu Y-M, Li Y-J, Zhang H-H, Pang M, Hu J-X, Zhao W, Xie N, Zhou L, et al. Smad3-related miRNAs regulated oncogenic TRIB2 promoter activity to effectively suppress lung adenocarcinoma growth. Cell Death Dis. 2016;7:e2528-e2528.

62. LinkW. Tribbles breaking bad: TRIB2 suppresses FOXO and acts as an oncogenic protein in melanoma. Biochem Soc Trans. 2015;43:1085-8.

63. Zanella F, Renner O, García B, Callejas S, Dopazo A, Peregrina S, Carnero A, Link W. Human TRIB2 is a repressor of FOXO that contributes to the malignant phenotype of melanoma cells. Oncogene. 2010;29:2973-82.
64. Chen Z, Chen J, Wa Q, He M, Wang X, Zhou J, Cen Y. Knockdown of circ_0084043 suppresses the development of human melanoma cells through miR-429/tribbles homolog 2 axis and Wnt/ $\beta$-catenin pathway. Life Sci. 2020;243:117323.

65. Xu S, Wu W, Huang H, Huang R, Xie L, Su A, Liu S, Zheng R, Yuan Y. Zheng $\mathrm{Hl}$ : the $\mathrm{p} 53 / \mathrm{miRNAs} / \mathrm{Ccna} 2$ pathway serves as a novel regulator of cellular senescence: complement of the canonical p53/p21 pathway. Aging Cell. 2019;18:e12918.

66. Hill R, Madureira PA, Ferreira B, Baptista I, Machado S, Colaco L, Dos Santos M, Liu N, Dopazo A, Ugurel S. TRIB2 confers resistance to anti-cancer therapy by activating the serine/threonine protein kinase AKT. Nat Commun. 2017:8:1-9.

67. Nag S, Zhang X, Srivenugopal KS, Wang MH, Wang W, Zhang R. Targeting MDM2-p53 interaction for cancer therapy: are we there yet? Curr Med Chem. 2014;21:553-74.

68. Wei G, Lu T, Shen J, Wang J. LncRNA ZEB1-AS1 promotes pancreatic cancer progression by regulating miR-505-3p/TRIB2 axis. Biochem Biophys Res Commun. 2020:528:644-9.

69. Liu C, Lu Z, Liu H, Zhuang S, Guo P. LnCRNA XIST promotes the progression of laryngeal squamous cell carcinoma via sponging miR-125b-5p to modulate TRIB2. Biosci Rep. 2020;40:BSR20193172.

70. Jaworska AM, Wlodarczyk NA, Mackiewicz A, Czerwinska P. The role of TRIM family proteins in the regulation of cancer stem cell self-renewal. Stem Cells. 2020;38:165-73.

71. Jiang C, Wei W, Wang Y, Song C, Pan L, Sun K, Du G, Deng Y, Tang G. TRIM21 causes abnormal expression of IL-6 in oral lichen planus via the TRIB2-MAPK signal axis. Am J Transl Res. 2020;12:4648-58.

72. Hassani S-N, Moradi S, Taleahmad S, Braun T, Baharvand H. Transition of inner cell mass to embryonic stem cells: mechanisms, facts, and hypotheses. Cell Mol Life Sci. 2019;76:873-92.

73. Etoc F, Brivanlou A. A boost towards totipotency for stem cells. Nat Cell Biol. 2019;21:671-3.

74. Zhao Y, Liu H, Zhao C, Dang P, Li H, Farzaneh M. Paracrine interactions involved in human induced pluripotent stem cells differentiation into chondrocytes. Curr Stem Cell Res Ther. 2020;15:233-42.

75. Zhao N, Sheng M, Wang X, Li Y, Farzaneh M. Differentiation of human induced pluripotent stem cells into male germ cells. Curr Stem Cell Res Therapy. 2020. https://doi.org/10.2174/1574888X15666200705214223.

76. Naiki T, Saijou E, Miyaoka Y, Sekine K, Miyajima A. TRB2, a mouse Tribbles ortholog, suppresses adipocyte differentiation by inhibiting AKT and C/ EBPbeta. J Biol Chem. 2007;282:24075-82.

77. Nakayama K, Iwamoto S. An adaptive variant of TRIB2, rs1057001, is associated with higher expression levels of thermogenic genes in human subcutaneous and visceral adipose tissues. J Physiol Anthropol. 2017;36:16.

78. Kim H-S, Oh SH, Kim J-H, Sohn W-J, Kim J-Y, Kim D-H, Choi S-U, Park KM, Ryoo ZY, Park TS. TRIB2 regulates the differentiation of MLL-TET1 transduced myeloid progenitor cells. J Mol Med. 2018;96:1267-77.

79. You D, Yang C, Huang J, Gong H, Yan M, Ni J. Long non-coding RNA MEG3 inhibits chondrogenic differentiation of synovium-derived mesenchymal stem cells by epigenetically inhibiting TRIB2 via methyltransferase EZH2. Cell Signal. 2019;63:109379.

80. Lu J, Li Y. Circ_0079593 facilitates proliferation, metastasis, glucose metabolism and inhibits apoptosis in melanoma by regulating the miR-516b/GRM3 axis. Mol Cell Biochem. 2020;475:227-37.

81. Liang Y, Yu D, Perez-Soler R, Klostergaard J, Zou Y. TRIB2 contributes to cisplatin resistance in small cell lung cancer. Oncotarget. 2017;8:109596.

82. Hou Z, Guo K, Sun X, Hu F, Chen Q, Luo X, Wang G, Hu J, Sun L. TRIB2 functions as novel oncogene in colorectal cancer by blocking cellular senescence through AP4/p21 signaling. Mol Cancer. 2018;17:1-15.

83. Richmond L, Keeshan K. Pseudokinases: a tribble-edged sword. FEBS J. 2020;287:4170-82.

\section{Publisher's Note}

Springer Nature remains neutral with regard to jurisdictional claims in published maps and institutional affiliations. 